\title{
The Implementation of Evidence-based Practice (EBP) and Information and Communication Technology (ICT)-based Health Care Information in Depok City: Stakeholders' Perspectives
}

\author{
Agus Setiawan ${ }^{1}$, Melati Fajarini ${ }^{2}$, Sri Rahayu $^{2}$, Enny Ekasari $^{3}$ \\ ${ }^{1}$ Faculty of Nursing, Universitas Indonesia \\ 2 Jayakarta Health Institute \\ ${ }^{3}$ Depok City Health Office
}

\begin{abstract}
Background: The role of stakeholders is imperative to support the implementation of Evidence Based Practice (EBP) and Information and Communication Technology (ICT)based health care information system. EBP and ICT is crucial to ensure that doctors and nurses provide care based on current and appropriate evidence.

Purpose: This study aimed to explore the implementation of EBP and ICT-based health care information access by doctors and nurses from the stakeholders' perspectives.

Methods: Semi structured interviews were conducted with 11 participants consisting of management representatives from Depok public hospital (RSUD), private hospitals, private clinics, and Depok city health office between November and December 2017. Data were recorded, transcribed, and analyzed thematically.

Findings: It was found that the availability and readiness of the ICT sources mostly sufficient; While the doctors and nurses are allowed to conduct research activities in the facility, none have conducted it; There are seminars and forums where doctors and nurses disseminate clinical cases in hospitals, however issues related to current EBP were hardly discussed; While the managements support doctors and nurses to implement EBP, there is no particular policy and funding allocated for research and training related to EBP; Public and private hospitals have clinical instructors, however their area of work are still mainly on assisting trainings and students practice.

Conclusion and Recommendations: There is a scant of EBP implementation in health care facilities in Depok city. However, several potentials of EBP enhancement are identified in terms of ICT, scientific forum, and the willingness of the management to enhance EBP. Advocacy on policy and resource arrangement is urged so that health workers would enhance their practice based on current evidence.
\end{abstract}

Keywords: evidence-based practice; health care information; information and communication technology;

\section{*Corresponding author:}

- Name : Agus Setiawan

- E-mail:a-setiawan@ui.ac.id

- Institution: Faculty of Nursing, Universitas of Indonesia

\section{Introduction}

Evidence-based Practice (EBP) in the clinical practice is crucial. EBP as an integration of best evidence and clinical expertise in the delivery of service has many advantages (Sackett, Rosenberg, Gray, Haynes, \& Richardson, 1996; Sigma Theta Tau 
International, 2005). EBP has been proven to improve patient outcome (Joseph, 2007; Parran, 2004; Pearson et al., 2006), health workers' job satisfaction (Parran, 2004), autonomy and credibility. Furthermore, it sets the base of clinical guidelines (T. J. Turner, 2009) and enhance cost effective care.

However, its practice in clinical workwere reported inadequate (McDonald et al., 2010). South East Asia Optimising Reproductive and Child Health in Developing Countries (SEA-ORCHID) project has analyzed that the mortality of mothers and infants in several countries South East Asia region, including Indonesia, were caused by inappropriate clinical practice. It was further rooted by the lack of access to quality health care information and skills in generating and synthetizing evidence. Moreover, 50\% of doctors, nurses and midwives have no access to computers and internet, and $48 \%$ have never heard of evidencebased. The World Health Organization (WHO) recommended broader access to health care information to enhance EBP (United Nations, 2015; WHO-SEARO, 2016). Unfortunately, this access is still inadequate (United Nations, 2015), also most doctors and nurses in South East Asia region have difficulties to access it through Information and Communication Technology (ICT) (Martis, Ho, \& Crowther, 2008; McDonald et al., 2010; T. J. Turner, 2009).

Furthermore, McDonald et al. (2010) and (T. J. Turner, 2009) listed several barriers in implementing EBP. Time constraints, major disparities in undergraduate education between health professionals, lack of capacity in discovering, appraising and interpreting evidence, lack of access to relevant evidence, difficulty arranging meetings and achieving consensus were reported in these studies. Health providers needs to overcome these barriers to implement EBP.

The stakeholders' role is imperative to enhance EBP. Health system are built by resources which supports it to establish (World Health Organization, 2017), in which EBP is a part of this system. Skilled and motivated health professionals, well maintained infrastructure, the availability of fund, strong policy and leadership are enablers resources (World Health Organization, 2010). Of the keys to strengthen health care delivery is to manage health professionals (Centers for Disease Control and Prevention, 2001) and the resources. Therefore, efforts to embed EBP implementation is placed upon the health providers' leaders and managers. Hence, it is crucial understand EBP implementation from the stakeholders' point of view.

Martis et al. (2008) and McDonald et al. (2010) studies were conducted towards several countries and health professionals. Little is known about how EBP established by Indonesian doctors and nurses especially from the stakeholders' perspective. This study was conducted to acquire how EBP is supported from the stakeholders' perspectives.

\section{Methods}

This study used a mixed method, conducted between November and December 2017 at health care providers in Depok City. However, only the qualitative results are presented in this paper. A proportional probability sampling was assigned to select the health care providers. The selected providers are Depok public hospital (RSUD), five private hospitals, five private clinics, and eleven district primary health care. Then, from the health providers selected, management representatives with at least one-year experience working at those health providers were purposively chosen for interviews. For interviews, the district primary health care represented by Depok city health office. Participants were provided with explanatory statement and informed consent was obtained.

Semi structured, face to face interviews were conducted. The interview followed a preinterview protocol. Participants were asked 22 questions developed from the WHO's Health 
system components (World Health Organization, 2010). Of the six WHO's health system components, five were assigned as a framework of this study. How is the EBP facilitated by the providers, how is their support on nurses and doctors to conduct research, how is the information system performed, how is the fund allocated and how is leadership and governance support EBP are the question topics from the health system. Interviews were audio-recorded by researchers or enumerators. Data were transcribed and analyzed thematically by a transcriber prior reviewed by the researcher.

\section{Results}

11 participants involved in this study. Almost all providers agreed to be interviewed except a clinic. The Depok City Primary Healthcare Center (PHC) were represented by the Depok City Health Department. Respondents comprises as managers of training or nurse managers or medical committee managers. Five themes emerged from this study including EBP services, healthcare workforce, health information system, EBP funding, leadership and government.

\section{EBP Services: Availability and accessibility}

Information and Communication Technology (ICT) devices such as computers and the internet are provided in the health facilities. Although some limitation of certain websites and internet outreach, access to evidence is widely opened. A hospital and a clinic provides tablet while another hospital provides smartphones. However, they are mostly utilized for communication. A participant said:

"Every ward has at least a computer with the internet accessible for doctors and nurses. However, it is used mainly for communication" [ Staff of Education and Training Department (ETD), Hospital, Male]. This was also supported by other participant who conveyed: "...some sites are blocked, but article browsing is allowed”. [Staff of ETD, Hospital, Female].

The management urged nurses and doctors to possess the ability to operate the computers, as been mentioned by a participant: ".....all doctors and nurses should have the ability to work with computer and internet." [ Staff of Health Care Services, Depok City Health Department, Female.], "We have computers and a tablet for everyone to use in the clinic. Internet can be used to search articles". [Owner of a clinic, Clinic, Female].

In addition to ICT facilities, all hospitals have Education and Training Department ETD. A Nurse manager in Depok City Hospital conveyed that "We have ETD for all professionals, in which the programs are planned by each affiliation...". However, none of the Puskesmas nor the clinics have it.

Most hospital does not have library even though they have books. Some PHC has library with kids books in it. None of the clinics has library. One hospital has a library with sufficient infrastructure such as books, e-books, a computer facilitated with internet, but no librarian. However, only a few doctors and nurses have utilized it.

"We have numerous books but we do not have a library”. [Staff of ETD, Hospital, Female].

"We don't have books and library”. [ Owner of a clinic, Clinic, Male].

"Some PHC has libraries, but they contain books for children to read". [ Staff of Health Care Services, Depok City Health Department, Female]. 


\section{Healthcare Workforce}

All health care providers expressed that they will support doctors and nurses to conduct research. However, most research was done when they undergo the pre service training. There was no research conducted by the other than education yet.

"Our hospital would love to have doctors and nurses conducting research within our hospital..." [Staff of ETD, Hospital, Male].

\section{Health Information System}

There are forums to discuss cases with various names across hospitals regularly or incidentally. One hospital provides training for article writing and searching. Also, another hospital establishes discussion forums and invites external speakers to discuss evidence. There is also an obligation to share the result of trainings undergone.

"... the forums usually discuss cases that we think it needs to be audited..." [Staff of ETD, Hospital, Female].

"Pre-conference at the ward are undergone every shift exchange to discuss cases. Then we also have inter-professional round once a month. For doctors, there is case discussions every Wednesday at the medical committee meeting. Or if there is an urgent case, we will be held the meeting. For the latest scientific inventions, we seldom invite experts from outside the hospital to share or promote something new." [Nurse manager, Depok City Hospital, Female].

"There are several external invitations to seminars from professional associations or clinic associations or pharmacy companies”. [Owner of a clinic, Clinic, Male].

\section{EBP Funding}

Funds for research, EBP trainings, libraries and journal magazines have not yet allocated in almost all providers. One hospital has research fund and another hospitals has fund allocated for article writing competition. Most providers have funds for ICT.

"Research are funded by the researcher... there are seminar invitations so seminar fees are usually waived by the organizer.... We do not have any library so there is no fund allocated for that and it need space... there is no fund for journal magazines.... We have to use computers and internet, so we have fund for computers and internet usage" [Owner of a clinic, Clinic, Male].

"Funds are filed from staff or units to ETD. There will consideration.... research is personal matters, so there is no fund allocated yet”. [Staff of ETD, Hospital, Male].

“We have funds allocated for ICT”. [Staff of Health Care Services, Depok City Health Department, Female]. 


\section{Leadership and Governance}

Five hospitals have Clinical Instructors (CI) and its policy in which CI recently formed in two hospitals. Most CI tasks are guiding students and discussing cases in which new evidence are included in the discussion. On the other hand, neither clinics nor PHC have CI.

"Both doctors and nurses have clinical instructors working under policy". [Staff of ETD, Hospital, Male].

“.. clinical instructors are just recently appointed. Staff of ETD, Hospital, Female.

"We do not have clinical instructors". Staff of Health Care Services, Depok City Health Department, Female.

"We have CI for clinical practice, internship and students.... CIs discuss case study or scholarly discussion”. Nurse managers and medical committee, Depok City Hospital, Females.

Hospitals also have policy for forums. One hospital has clinical guidelines based on the latest information and has forums to share these guidelines amongst CIs.

"Policy on scholastic forums are expressed in hospital organizational guidelines" Staff of ETD, Hospital, Male.

\section{Discussion}

Health care providers have made ICT available and accessible for healthcare workers. The ICT infrastructures in Depok City are in place with opened access for doctors and nurses. However, readiness to utilize ICT to find evidence is inadequate despite the fact that technology in health care has a broad range of usage (Jones, Rudin, Perry, \& Shekelle, 2014). ICT is merely utilized as a communication tools and there has not been trainings on online researching skills. Internet penetration and usage to find health care information is high (Asosiasi Penyelenggara Jasa Internet Indonesia, 2017; CIGI-Ipsos, 2017), this opportunity should be managed by stakeholders to enhance the ICT utilization for EBP across health care providers.

Other supporting EBP infrastructures need be improved are the role of the ETD and access to evidence. The availability of ETD and article resources are greater in hospitals compared to PHCs and clinics. Measures should be taken to enhance hospitals readiness to embed EBP by implanting ETD programs on research translation, synthesis and research itself. More article magazines or online resources should be accessible for doctors and nurses. These are similar enablers recognized from T. Turner and Short (2013) research. Whilst, primary health care still needs to provide these infrastructures. ETD, article resources and library should be made available in primary health care.

Health care information system is more established in secondary health care compared to the primary health care. In the hospital, health care information is shared regularly. Although some managers claimed that these forums discussed journal articles, the majority said that they are mainly focused on clinical cases. These forums are also supported by the management and policy. On the other hand, health care information in the primary health care settings is depending on external support. One of the reasons hospitals have the privilege to establish the forum is because the time constraint. The health care worker at 
Puskesmas have to serve patients not only in the facility, but they also need to conduct outreach activities.

Establishing a forum where practitioners can disseminate and discuss evidence is important. The forum would enable doctors and nurses to learn from each other regarding the use of current evidence and the challenge they may encounter to implement certain clinical intervention. The forum would also beneficial in increasing the practitioners' confidence in implementing evidence into practice. Health care information system can set the base of clinical decision (World Health Organization, 2010), thus this system is imperative for the stakeholders to manage.

Another imperative factor to ensure the continuity of EBP implementation is the support from the management or leader in the health service provider (Stetler, Ritchie, RycroftMalone, \& Charns, 2014). All stakeholders have expressed their willingness to help doctors and nurses for researching. Also, the support can be reflected by the funding allocated for the program. However, unlike ICT, EBP and research still rank less priority fund. The funding allocation should be viewed as long term investment that would be beneficial for health service quality improvement, and eventually contribute to positive patient outcome.

In implementing EBP, CIs played a big role in the continuity of information in the clinical area (Milner, Estabrooks, \& Myrick, 2006). Leaders are mentors (Northouse, 2010) whom in the context of research utilization enhance the knowledge translation. Especially nurses, previous studies noted that knowledge is best delivered by people or social sources compared to other information media (Estabrooks, Chong, Brigidear, \& Profetto-McGrath, 2005; Larsen, Adamsen, Bjerregaard, \& Madsen, 2002; Thompson et al., 2001). However, several factors hindered this role such as the lack of support in performing this role, trainings and time (Burns \& Northcutt, 2009; Hallin \& Danielson, 2009; Pollard, Ellis, Stringer, \& Cockayne, 2007). Support and trainings are needed to enhance this important role (Horton, DePaoli, Hertach, \& Bower, 2012; McClure \& Black, 2013). Stakeholders determine the success of preceptor support system (Goss, 2015) in the knowledge translation area. As well, the nurses' legitimation of knowledge through policies are needed (Manias \& Street, 2000).

\section{Conclusion}

The implementation of EBP in health care facilities in Depok city has, to some extent, has been done. However, several potentials of EBP enhancement are identified in terms of ICT, scientific forum, and the commitment of the leaders to improve EBP. Advocacy on policy and resource arrangement is advised so that health workers could enhance their practice based on current evidence.

\section{Acknowledgements}

This study was undertaken within the project of World Class University at University of Indonesia, funded by Joint Research Cooperation " Depok City Health Development ". We also would like to thank all contributors involved in this study.

\section{References}

Asosiasi Penyelenggara Jasa Internet Indonesia. (2017). Infografis: Penetrasi dan perilaku pengguna internet Indonesia, Survey 2017. Jakarta: Asosiasi Penyelenggara Jasa Internet Indonesia.

Burns, H. K., \& Northcutt, T. (2009). Supporting preceptors: A three-pronged approach for success. The Journal of Continuing Education in Nursing, 40(11), 509-513.

Centers for Disease Control and Prevention. (2001). Program review. from http://www.phppo.cdc.gov/owpp/docs/library/2001/PHPP\%20Program\%Review\%202001.pdf 
CIGI-Ipsos. (2017). Global survey on internet security and trust: Center for International Governance Innovation.

Estabrooks, C. A., Chong, H., Brigidear, K., \& Profetto-McGrath, J. (2005). Profiling Canadian nurses' preferred knowledge sources for clinical practice. CJNR (Canadian Journal of Nursing Research), 37(2), 118141.

Goss, C. R. (2015). Systematic review building a preceptor support system. Journal for Nurses in Professional Development, 31(1), E7-14. doi: http://dx.doi.org/10.1097/NND.0000000000000117

Hallin, K., \& Danielson, E. (2009). Being a personal preceptor for nursing students: Registered Nurses' experiences before and after introduction of a preceptor model. Journal of Advanced Nursing, 65(1), 161-174. doi: doi:10.1111/j.1365-2648.2008.04855.x

Horton, C. D., DePaoli, S., Hertach, M., \& Bower, M. (2012). Enhancing the effectiveness of nurse preceptors. Journal for Nurses in Professional Development, 28(4), E1-E7. doi: 10.1097/NND.0b013e31825dfb90

Jones, S. S., Rudin, R. S., Perry, T., \& Shekelle, P. G. (2014). Health information technology: An updated systematic review with a focus on meaningful use. Annals of Internal Medicine, 160(1), 48-54. doi: $10.7326 / \mathrm{M} 13-1531$

Joseph, A. M. (2007). The impact of nursing on patient and organizational outcomes. Nursing Economics, 25(1), 30-34.

Larsen, K., Adamsen, L., Bjerregaard, L., \& Madsen, J. K. (2002). There is no gap 'per se' between theory and practice: Research knowledge and clinical knowledge are developed in different contexts and follow their own logic. Nursing Outlook, 50(5), 204-212. doi: 10.1067/mno.2002.127724

Manias, E., \& Street, A. (2000). Legitimation of nurses' knowledge through policies and protocols in clinical practice. Journal of Advanced Nursing, 32(6), 1467-1475. doi: doi:10.1046/j.1365-2648.2000.01615.x

Martis, R., Ho, J. J., \& Crowther, C. A. (2008). Survey of knowledge and perception on the access to evidencebased practice and clinical praktice change among maternal and infant health practitioners in South East Asia. BMC Pregnancy and Childbirth, 8(34), 1-10.

McClure, E., \& Black, L. (2013). The role of the clinical preceptor: An integrative literature review. Journal of Nursing Education, 52(6), 335-341. doi: http://dx.doi.org/10.3928/01484834-20130430-02

McDonald, S., Turner, T., Chamberlain, C., Lumbiganon, P., Thinkhamrop, J., Festin, M. R., . . Green, S. (2010). Building capacity for evidence generation, synthesis and implementation to improve the care of mothers and babies in South East Asia: methods and design of the SEA-ORCHID Project using a logical framework approach. BMC Medical Research Methodology, 10(61), 1-10.

Milner, M., Estabrooks, C. A., \& Myrick, F. (2006). Research utilization and clinical nurse educators: a systematic review. Journal of Evaluation in Clinical Practice, 12(6), 639-655.

Northouse, P. G. (2010). Leadership: Theory and practice (5rd ed.). London: Sage.

Parran, L. (2004). Evidence-based management yields improved care and high nurse satisfaction. ONS News, 19(7), 1.

Pearson, A., Porritt, K. A., Doran, D., Vincent, L., Craig, D., Tucker, D., . . Henstridge, V. (2006). A comprehensive systematic review of evidence on the structure, process, characteristics and composition of a nursing team that fosters a healthy work environment. International Journal of Evidence-Based Healthcare, 4(2), 118-159.

Pollard, C., Ellis, L., Stringer, E., \& Cockayne, D. (2007). Clinical education: A review of the literature. Nurse Education in Practice, 7(5), 315-322. doi: 10.1016/j.nepr.2006.10.001

Sackett, D. L., Rosenberg, W. M. C., Gray, J. A. M., Haynes, R. B., \& Richardson, W. S. (1996). Evidence based medicine: What it is and what it isn't. BMJ, 312(7023), 71-72.

Sigma Theta Tau International. (2005). Evidence-based Nursing position statement. Retrieved 19th April, 2017, from https://www.nursingsociety.org/connect-engage/about-stti/position-statements-and-resourcepapers/evidence-based-nursing-position-statement

Stetler, C. B., Ritchie, J. A., Rycroft-Malone, J., \& Charns, M. P. (2014). Leadership for evidence-based practice: strategic and functional behaviors for institutionalizing EBP. Worldviews Evid Based Nurs, 11(4), 219-226. doi: 10.1111/wvn.12044

Thompson, C., McCaughan, D., Cullum, N., Sheldon, T. A., Mulhall, A., \& Thompson, D. R. (2001). The accessibility of research-based knowledge for nurses in United Kingdom acute care settings. Journal of Advanced Nursing, 36(1), 11-22.

Turner, T., \& Short, J. (2013). Barriers to and enablers of evidence-based practice in perinatal care in the SEA-ORCHID project. Journal of Evaluation in Clinical Practice, 19(4), 591-597. doi: doi:10.1111/j.1365-2753.2011.01810.x

Turner, T. J. (2009). Developing evidence-based clinical practice guidelines in hospitals in Australia, Indonesia, Malaysia, the Philippines and Thailand: values, requirements and barriers. BMC Health Services Research, 9(1), 235. doi: 10.1186/1472-6963-9-235

United Nations. (2015). The millennium development goals report 2015. In United Nations (Ed.). New York. 
WHO-SEARO. (2016). Evaluation of WHO's contribution to maternal health in the South-East Asia Region. In WHO-SEARO (Ed.). India: World.

World Health Organization. (2010). Monitoring the building blocks of health systems: A handbook of indicators and their measurement strategies. Geneva, Switzerland: WHO Press.

World Health Organization. (2017). Health systems. About. Retrieved 24th April 2017, from http://www.who.int/healthsystems/about/en/ 